\title{
凝固異常が疑われた外傷性出血に対して NBCA-TAEを施行した2例
}

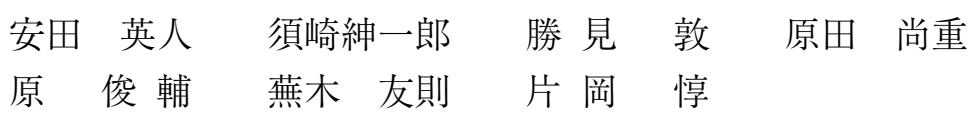

\begin{abstract}
要旨 近年，外傷に扔ける出血性ショックに対して外科的治療と並んで血管内治療（intravascular radiology: IVR）が選択されることが増加している。N-butyl-2-cyanoacrylate（NBCA）は，低価格 で塞栓時間の短縮，塞栓の確実性が得られ，患者の凝固能力に依存しない塞栓物質であるという 特徴から, 凝固異常を来した外傷性出血に対して有用な手段と考えられる。今回我々は, 凝固異 常が疑われた外傷性出血性ショックに対してNBCAによる経カテーテル動脈塞栓術が有効であっ た症例を経験したので報告する。症例 1 は交通外傷による骨盤骨折により出血性ショックを来し た70歳台の男性の症例であった。凝固検査の結果や抗血小板薬の内服により出血傾向に至る可 能性があったことから，NBCAによる右内腸骨動脈塞栓を施行した。速やかな止血が得られ状態 は安定した。症例 2 は右側腹部打撲による腎損傷により出血性ショックを来した 80 歳台女性の症 例であった。凝固異常がみられ，後腹膜のタンポナーデ効果に対する懸念があったことから， NBCAによる右腎動脈塞栓を施行した。その後速やかにバイタルサインの安定が得られた。両症 例とも凝固異常がみられた症例に対してNBCAが功を奏した症例であった。外傷性出血に対する 経カテーテル動脈塞栓術（transarterial embolization: TAE）の際には患者の凝固能力に応じた塞栓 物質の選択が重要となり，本症例のように出血傾向が懸念される場合にはNBCAを利用したTAE が有用と考えられる。
\end{abstract}

(日救急医会誌. 2014; 25: 125-31)

キーワード：出血性ショック, 血管内治療, 塞栓物質

\section{はじめに}

外傷性出血は時にはコントロール不良に陥り，致 死的になる。その要因の一つとして凝固系が線溶立 進型を呈することが考えられる。そのような状況下 において近年経カテーテル動脈塞栓術（transcatheter arterial embolization: TAE）による止血が注目されてい る。塞栓物質の多くは患者の凝固能に依存するが, N-butyl-2-cyanoacrylate（NBCA）は患者凝固能には依

NBCA-TAE for traumatic bleeding with suspected coagulation abnormalities: a report of two cases

武蔵野赤十字病院救命救急センター

著者連絡先：干 180-8610 東京都武蔵野市境南町1-26-1

原稿受理日：2013年7月 1日（13-053）
存しない塞栓物質であり, 線溶无進状態でも良好な 止血が得られることで近年注目されている ${ }^{1-4)}$ 。本稿 では当院で経験した外傷性出血に対してNBCAを使 用した 2 症例を提示し, 外傷性出血におけるNBCATAEの有用性について報告する。

\section{症例}

症例 $1 ： 70$ 歳台の男性

既往歴 : 糖尿病, 延髄梗塞

内服歴：シロスタゾール, メトホルミン, シタグ

リプチンリン

現病歴：歩行中に乗用車と衝突し当院救命救急七 ンターへ搬送された。

来院時現症：バイタルサインは, GCS E1V1M3, 


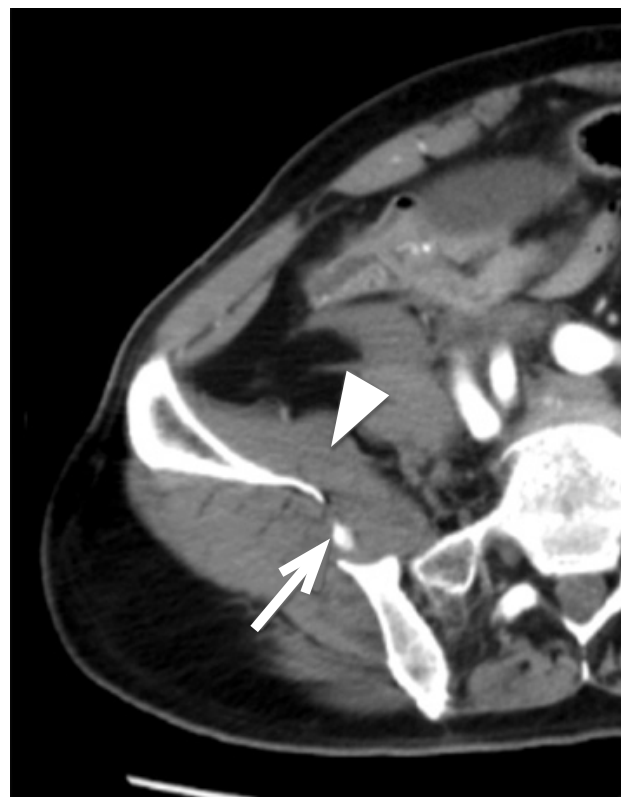

a: Case 1

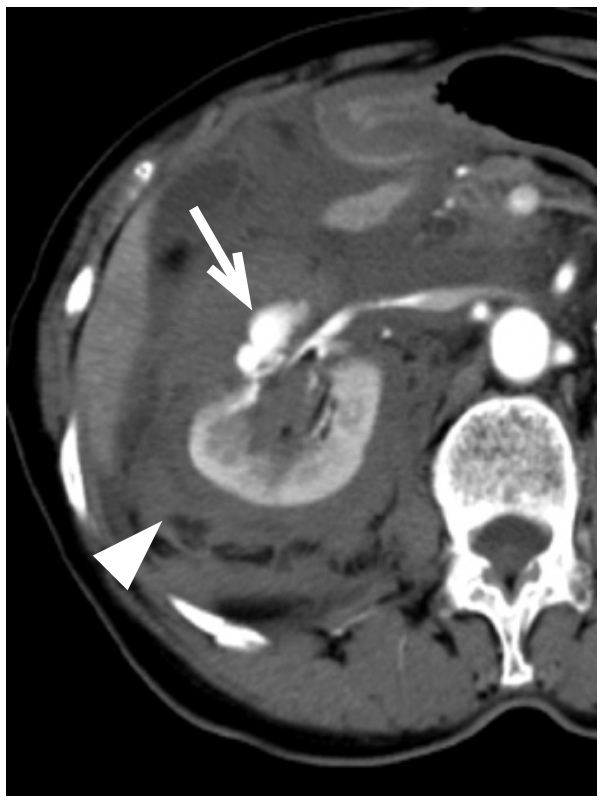

b: Case 2

Fig. 1. Enhanced computed tomography on admission of Cases 1 and 2.

a: Fracture is apparent at the right wing of the ilium, surrounded by hematoma (arrow head) and extravasation of contrast medium (arrow).

b: Extravasation of contrast medium (arrow) with massive hematoma (arrow head) is observed around the right kidney.

血圧 $74 / 36 \mathrm{mmHg}$, 心拍数 $125 /$ 分, 呼吸数 $20 /$ 分, 体 温 $36.7^{\circ} \mathrm{C}$ (腋窩温), 瞳孔左右 $6 \mathrm{~mm}$ 対光反射両側鈍, $\mathrm{SpO}_{2} 99 \%$ (10L/分酸素マスク）であった。

意識障害を認めたが気道は開通しており，呼吸に 異常はなかった。四肢末梢は冷たく湿潤しており， ショックが考えられた。胸部レントゲンに異常は認 めなかったが，骨盤レントゲンで右腸骨翼・右恥座 骨折を認めた。 focused assessment with sonography for trauma（FAST）では明らかな液体貯留を認めなかっ た。初期輸液により血圧上昇を認めたことから頭部 単純CT 検査および頸部から骨盤部までの造影CT検 查を施行した。

CT所見：頭部 CT 検査では外傷性くも膜下出血, 脳挫傷を認めた。胸腹部に明らかな出血性損傷は認 めなかったが, 右腸骨翼および右恥座骨骨折（包括 的骨盤骨折分類 $\mathrm{C} 1$ : 片側完全不安定型）を認め, 同 部位の後復膜腔に血管外漏出像（extravasation）を 伴う多量の血腫を認めた（Fig. 1a）。

以上の所見より，骨盤骨折による出血性ショック
および頭部外傷による意識障害と診断し，輸液によ り血圧上昇はあるものの造影剤の血管外漏出像が認 められたことから両側内腸骨動脈の TAEを施行す る方針とした。

血管造影および塞栓術 : 左大腿動脈より $5 \mathrm{Fr}$ short sheath を挿入し，5Frコブラ型カテーテルを使用した。 右内腸骨動脈を選択的に造影すると， CT と一致する 箇所の右上殿動脈本幹より extravasationを認めた (Fig. 2a)。extravasationが高度であり血圧が低下傾向であっ たこと，患者が高齢である上に抗血小板薬の内服を していたこと，さらに凝固系検査異常（PT-INR 0.93 秒，APTT 27.8秒， Fib 188mg/dl， D-ダイマー $60.9 \mu \mathrm{g} /$ $\mathrm{ml}$, FDP $81.7 \mu \mathrm{g} / \mathrm{ml}$ ）を認めたことから, 確実な止血 が必要であると判断し，NBCAを使用する方針とし た。右内腸骨動脈本幹から NBCA-Lipiodol（1:5）で 塞栓し, extravasationの消失を認め (Fig. 2b), その後 から血圧の安定を得た。左内腸骨動脈は明らかな extravasationを認めなかったが右内腸骨動脈との吻合枝 を考慮し, 左内腸骨動脈本幹からゼラチンスポンジ 


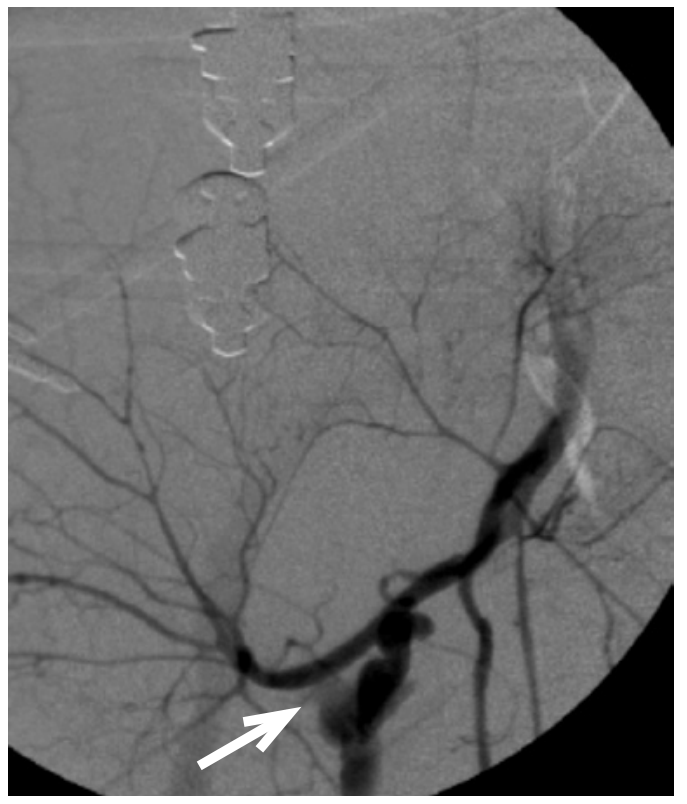

a: extravasation

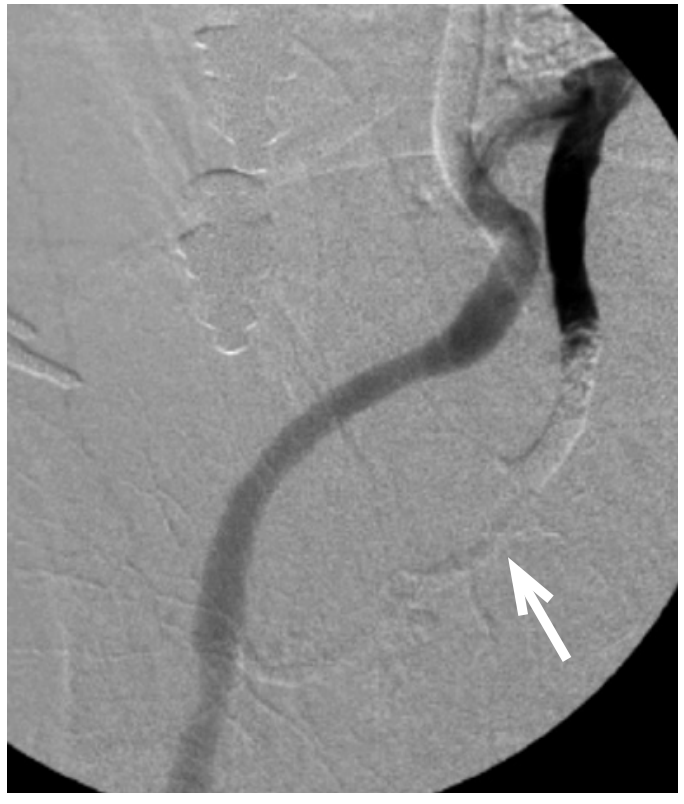

b: post TAE

Fig. 2. Angiography of the right internal iliac artery in Case 1.

a: Angiography of the right internal iliac artery reveals extravasation of contrast medium (arrow) at the main branch of the superior gluteal artery.

b: Angiography after transcatheter arterial embolization (TAE) shows occlusion of the right internal iliac artery following embolization with N-butyl cyanoacryl (NBCA) (arrow).

で塞栓した。血管造影開始から塞栓終了まで（以下， 手技時間）に5分 15 秒を要した。

術後経過：TAE後は循環動態安定を認めた。不安 定型骨盤骨折のために創外固定で骨盤輪の安定を 図った。意識障害が遷延したことから後日MRI検 查を施行し, び慢性軸索損傷の診断となった。リハ ビリ目的に第93日目に転院となった。

\section{症例 $2: 80$ 歳台の女性}

既往歴：乳癌, 大腸癌

内服歴：アナストロゾール

現病歴：自宅内で転倒し右側胸部および側腹部を 打撲した。その後, 腹壁緊張所見を認めたことから 当院救命救急センターへ搬送となった。

来院時現症：バイタルサインは, GCS E3V4M6, 血圧 $97 / 60 \mathrm{mmHg}$, 心拍数 $101 /$ 分, 呼吸数 $23 /$ 分, 体 温 $35.8^{\circ} \mathrm{C}$ (腋窩温), 瞳孔左右 $3 \mathrm{~mm}$ 対光反射両側迅 速, $\mathrm{SpO}_{2} 93 \%$ （室内気）であった。

意識は清明で発語があり気道は開通，呼吸に異常
はなかった。四肢末梢は冷たく湿潤しておりショッ ク状態であった。麻痺および四肢の外表面上の出血 はなかった。胸部レントゲンでは右第 4,5 肋骨骨折 を認めたが，明らかな血気胸は認めなかった。骨盤 レントゲンに明らかな異常はなかった。FASTでは 明らかな液体貯留は指摘できなかったが, 右腎周囲 に低〜等エコー域を認めた。

Secondary surveyでは右胸部および側腹部に打撲 痕および圧痛を認め，上記の所見と合わせて右腎損 傷が疑われたために頭部単純 CT 検査および頸部か ら骨盤部までの造影CT検査を施行した。

来院時造影 $\mathrm{CT}$ 所見: 右胸腔に少量の液体貯留, 右第 4,5 肋骨骨折を認めた。右腎に周囲の後腹膜腔 に多量の血腫および extravasationを伴う IIIt 型腎損 傷を認めた（Fig. 1b）。

以上の所見より右IIIl型腎損傷による出血性ショッ クと診断した。初期細胞外液 $3,000 \mathrm{ml}$ 投与するも徐々 に血圧の低下を認めた。しかし CT 検査より右腎損 傷単独であったために TAEでの止血方針とした。 


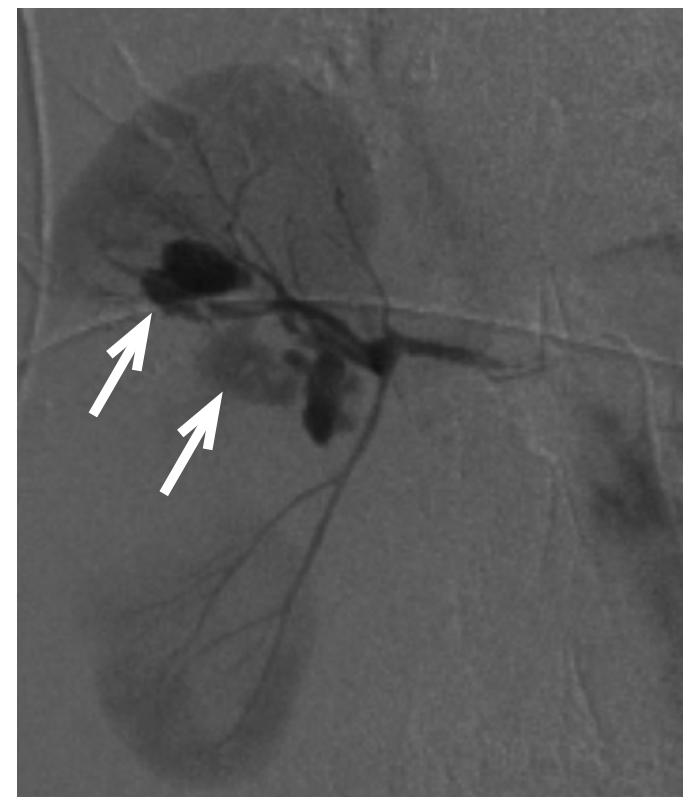

a: extravasation

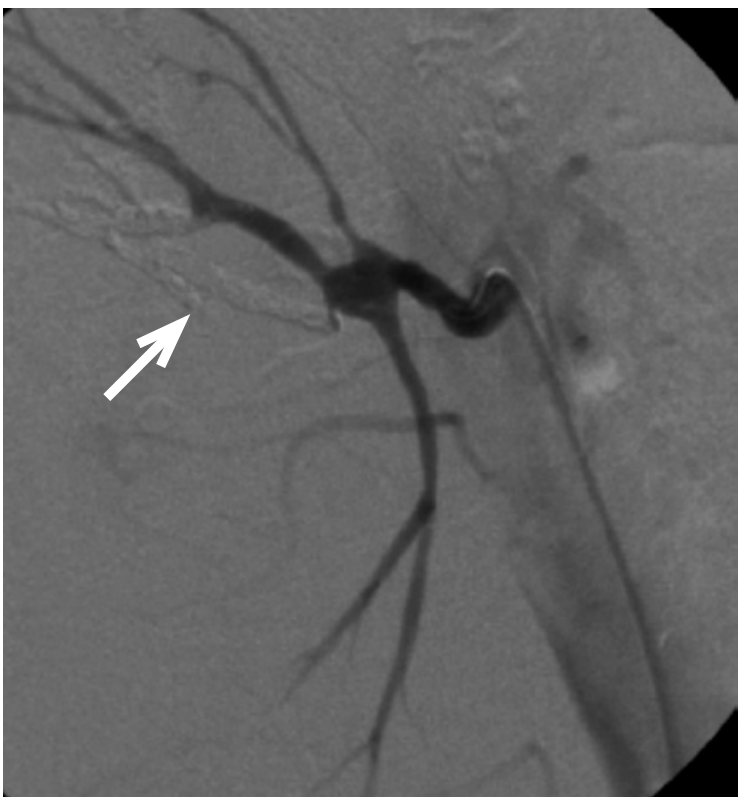

b: post TAE

Fig. 3. Angiography of the right renal artery in Case 2.

a: Angiography of the right renal artery reveals extravasation of contrast medium at two or more branches of the right renal artery (arrow).

b: Angiography after TAE shows occlusion of the same branch of the right renal artery following embolization with NBCA (arrow).

血管造影および塞栓術：右大腿動脈より 5Fr long sheath を挿入し，5Frコブラ型バルーンカテーテルを 使用した。出血性ショックが持続する場合にはバ ルーンを拡張し右腎動脈血流を遮断する方針とし た。右腎動脈を選択的に造影すると， CT と一致する 箇所に右腎動脈末梢の複数の枝から extravasationを認 めた（Fig. 3a)。IIlb 型腎損傷であり重症度が高かっ たこと, 軽度の凝固系検査異常 (Plt $11.5 \times 10^{4} / \mu \mathrm{l}$, Fib $178 \mathrm{mg} / \mathrm{dl}$, D- ダイマー $17.3 \mu \mathrm{g} / \mathrm{ml}$ ) を認めたこと, さらに高齢であることから確実な止血が必要である と判断し, NBCAを使用する方針とした。右腎動脈 枝3本に分けてNBCA-Lipiodol（1:3）で塞栓し, 造 影剂の血管外漏出像の消失を認め (Fig. 3b), その 後から血圧の安定を得た。手技時間は 8 分 20 秒で あった。

術後経過：TAE後は循環動態が安定した。術後は 循環動態共に経過良好であったが，尿漏が持続し， 発熱などから拡大した尿囊腫（urinoma）への感染 が疑われたために腎摘出が妥当であると判断して第
8病日に右腎摘出術を施行した。その後は合併症な く順調に回復し，第20病日に独歩退院となった。

\section{考察}

昨今では血管内治療（interventional radiology: IVR） の進歩により外傷性出血性ショック症例に対しての IVRの適応が拡大している ${ }^{1-4)}$ 。しかし外傷性出血に おける TAEは通常のIVR とは異なり, 緊急性が高く 凝固異常を認める場合が多い点に注意が必要であ る。IVRに使用される塞栓物質はゼラチンスポンジ やマイクロコイルのように患者の凝固能力を利用し て塞栓を行うものが主流である。しかし外傷性出血 の際には持続する出血により, 患者の凝固が線溶抑 制傾向から線溶立進傾向に傾きゼラチンスポンジや マイクロコイルでは凝固が得られずに止血困難な場 合がある ${ }^{5,6)}$ 。そのような場合には患者の凝固能力に は依存しない塞栓物質, つまり NBCAの有用性が注 目される。

凝固異常が認められる症例に対してNBCAが有効 
であるとする研究は多数報告されている。Yonemitsu ら ${ }^{7)}$ は凝固異常（血小板 5 万/ $/ \mu 1$ 以下, PT-INR 1.5 以上）を呈している動脈性出血症例 46例に対して ゼラチンスポンジ，マイクロコイル， NBCAの3つ の塞栓物質で止血成功率, 再出血の割合, 止血時間 を比較した。止血成功率および再出血率はそれぞれ $67 \%, 80 \%, 100 \%(\mathrm{p}=0.009), 23 \%, 0 \%, 0 \%(\mathrm{p}=0.048)$ であり NBCA で確実に止血が得られた。また血管造 影開始から止血までの時間を比較すると，それぞれ で $25 \pm 10$ 分, $37 \pm 19$ 分, $9 \pm 4$ 分であり, NBCA で有 意に止血時間が短縮していた（p<0.0001）。その他 にも動物実験ではあるが凝固能が破綻している場合 にはゼラチンスポンジによる止血では再出血が多い との報告 ${ }^{8)}$ (ゼラチンスポンジ $80 \%$ vs. NBCA 20\%) や, 凝固異常時におけるゼラチンスポンジやマイク ロコイルでの止血成功率は $40 \%$ 程度との報告 ${ }^{9)}$ も散 見される。本稿で報告した当院の 2 症例でも血管造 影から止血完了までそれぞれで約5分，8分という 短時間であった。

これまでの知見を参考にすると，NBCAはゼラチ ンスポンジよりも確実な血管塞栓が得られ，かつマ イクロコイルより短時間での塞栓が可能な塞栓物質 と考えられる。しかし上記の研究だけでは凝固異常 時におけるNBCAの有用性を議論するのは不十分で あり, 抗血小板薬の使用や周囲組織のタンポナーデ 効果の有無なども考慮しなければならない。たとえ ば骨盤骨折の場合では高齢者の場合と若年者の場合 では後腹膜の組織の脆弱性が異なり, 高齢者の方が より出血が顕著になることが予想される。上記の知 見, IVR学会が推奨する適応 ${ }^{10)}$, さらに自験例を考慮 し, 出血性ショック時のNBCAの適応に関して我々 は以下のように考えている。1）出血点までカテーテ ル到達が困難もしくは時間を要する場合，2）動静脈 シャントのように動脈から静脈側まで塞栓を要する 場合，3）凝固能低下を認める場合，4）抗血小板薬 などの抗血栓性薬剤の投与がされている場合，5）解 剖学的位置や年齢を考慮したタンポナーデ効果が期 待できない場合などがNBCAのよい適応と考える。
つまり, 重症外傷や大量消化管出血症例など, 凝固 能低下から止血困難に陥りやすい状況で救命目的に 早急な塞栓止血が不可欠な場面では，NBCA 塞栓の 確実性・迅速性を念頭において積極的な使用を早期 から考慮すべきである。

しかしNBCAはいくつかの問題点を抱えている。 その一つに保険認可の問題がある。NBCAは薬事法 上, 皮膚欠損用創傷被覆材の一種として「医薬用品 (4)整形用品」に類別される。かつ, NBCA は本邦の 添付文書上では脳血管以外の血管内使用の有無の記 載がされておらず，その他の血管内投与については 禁忌・禁止項目に列挙されており, 現状ではNBCA の血管内投与は適応外使用として医師の裁量に任さ れている。

しかし臨床的需要度の増加を受けて, 日本IVR学 会から NBCAの有効性と必要性の提言が公表され た ${ }^{11)}$ 。その後に血管塞栓術に用いる NBCAのガイド ライン $20122^{10)}$ を発表し，その中で「NBCAはIVR 治療には不可欠であることは厳然たる事実である」 と述べている。NBCAの使用は医師の裁量に任され ているために，その使用には医師個人だけでなく施 設としてのコンセンサスも必要であり, 院内倫理委 員会拉よびインフォームドコンセントが必要不可欠 となる。添付文書に記載されていない使用方法によ り健康被害が起こった場合, 本邦の副作用被害救済 制度が適応されないという問題があるために，緊急 時に扮ける保険適応外使用に関して予め院内で十分 に協議し倫理委員会の承認を得て, さらになおかつ 緊急時使用に本人抢よび関係者への十分なイン フォームドコンセントを行って初めて使用が可能と なる塞栓物質であることをまずは念頭においておか なければならない。当院では予め NBCAの血管内使 用に関して院内倫理委員会の承認を得て, 緊急時に は患者および関係者への同意を得るように心がけて いる。

本稿で提示した症例では明らかな線溶㐫進型凝固 異常を呈していたわけではないが，抗血小板薬の内 服歴や高齢者であったことから早期止血が必要と判 
断し結果的にNBCAが奏功した症例であったと考え る。本症例のように早期の止血・凝固異常を来して いる症例の場合はNBCAの有用性があると考えられ る。しかし現段階でもはっきりとしたNBCAの適応 などは未だに提示されておらず，安全性も加味して 今後のさらなる考察が必要である。

\section{結語}

今回我々は，凝固異常が懸念される外傷性出血性 ショック症例に対してNBCAで良好に止血が得られ た2症例を経験した。患者凝固能を意識したIVRで はNBCAが有用であると考えられるが，十分な院内 体制の整備, 患者・家族へのインフォームドコンセ ントがNBCA使用には必要と考えられる。

本論文に利益相反はない。

\section{文献}

1) Kim J, Shin JH, Yoon HK, et al: Transcatheter renal artery embolization with N-butyl cyanoacrylate. Acta Radiologica. 2012; 53: 415-21.

2) Kanematsu M, Watanabe H, Kondo H, et al: Postpartum hemorrhage in coagulopathic patients: preliminary experience with uterine arterial embolization with N-butyl cyanoacrylate. J Vasc Interv Radiol. 2011; 22: 1773-6.
3) 藤中俊之, 中村元, 黒田淳子, 他: 緊急止血のために NBCAによる塞栓術が有用であった上顎顔面杙創の 1 例. JNET. 2009; 3: 192-7.

4) Yata $S$, Ihaya $T$, Kaminou $T$, et al: Transcatheter arterial embolization of acute arterial bleeding in the upper and lower gastrointestinal tract with N-butyl-2-cyanoacrylate. J Vasc Interv Radiol. 2013; 24: 422-31.

5) 丸藤哲, 澤村淳, 早川峰司, 他: 外傷急性期の血液凝固線 溶系.日救急医会誌. 2010; 21: 765-78.

6) 早川峰司, 和田剛志, 菅野正寛, 他: 鈍的外傷患者におけ る FDP (fibrin/fibrinogen degradation products) 高值と大量 出血の関連性.日救急医会誌. 2010; 21: 165-71.

7) Yonemitsu T, Kawai N, Sato M, et al: Evaluation of transcatheter arterial embolization with gelatin sponge particles, microcoils, and n-butyl cyanoacrylate for acute arterial bleeding in a coagulopathic condition. J Vasc Interv Radiol. 2009; 20: 1176-87.

8) Yonemitsu T, Kawai N, Sato M, et al: Comparison of hemostatic durability between N-butyl cyanoacrylate and gelatin sponge particles in transcatheter arterial embolization for acute arterial hemorrhage in a coagulopathic condition in a swine model. Cardiovasc Intervent Radiol. 2010; 33: 1192-7.

9) Schenker MP, Duszak R Jr, Soulen MC, et al: Upper gastrointestinal hemorrhage and transcatheter embolotherapy: clinical and technical factors impacting success and survival. J Vasc Interv Radiol. 2001; 12: 1263-71.

10) 日本IVR学会: 血管塞栓術に用いるNBCAのガイドライ ン 2012 : http://www.jsivr.jp/guideline/NBCA/130107_ NBCA.pdf Accessed by Oct 10, 2013

11) 日本IVR学会. 日本では血管内投与禁忌とされている塞 栓物質についてのステートメント: http://www.jsivr.jp/ jimukyoku/0805kekkan.pdf Accessed by Oct 10, 2013 


\author{
ABSTRACT \\ NBCA-TAE for traumatic bleeding with suspected coagulation abnormalities: a report of two cases \\ Hideto Yasuda, Shinichirou Suzaki, Atsushi Katsumi, Naoshige Harada \\ Shunsuke Hara, Tomonori Kaburaki, Jun Kataoka \\ Department of Emergency and Critical Care Medicine, Japanese Red Cross Musashino Hospital
}

Interventional radiology (IVR) has increasingly been selected for traumatic hemorrhagic shock. N-butyl-2-cyanoacrylate (NBCA) is an effective measure for traumatic hemorrhage with coagulation abnormality due to the its property as a embolization material, independent of the patient's individual clotting ability and the shorter embolization time. Two cases in which transcatheter arterial embolization (TAE) using NBCA was effective for traumatic hemorrhagic shock in patients with suspected coagulation abnormalities are reported. Case 1 was a man in his 70s who developed hemorrhagic shock following a pelvic fracture caused by a traffic injury. NBCA embolization of the right internal iliac artery was performed based on the results of the coagulation test and the possibility that oral administration of antiplatelet agents may increase the bleeding tendency. Case 2 was a woman in her 80s who developed hemorrhagic shock following a renal injury that was caused by a bruise on the right side of her abdomen. In addition, loss of the tamponade effect within the retroperitoneum was a concern due to the advanced age; therefore, NBCA embolization of the right renal artery was performed. In both cases, NBCA was effective. TAE using NBCA may be effective in cases at risk of fibrinolytic-type disseminated intravascular coagulation (DIC).

(JJAAM. 2014; 25: 125-31)

Keywords: hemorrhagic shock, intravascular radiology (IVR), embolization material

Received on July 1, 2013 (13-053) 